\title{
AN ATOM-PROBE STUDY \\ OF SOME FINE-SCALE MICROSTRUCTURAL FEATURES \\ IN NI-BASED SINGLE CRYSTAL SUPERALLOYS
}

\author{
D. BLAVETTE* ${ }^{*}$ P. CARON** and T. KHAN $^{* *}$
}

* Faculté des Sciences de Rouen, Laboratoire de Microscopie Ionique

UA 808 CNRS, UFR des Sciences \& Techniques

B.P. 118, 76134 MONT SAINT AIGNAN CEDEX, FRANCE

** Office National d'Etudes et de Recherches

Aérospatiales (ONERA)

B.P. 72, 92322 CHATILLON CEDEX, FRANCE

\section{ABSTRACT}

Some fine-scale microstructure of nickel-based single crystal superalloys have been investigated by means of atom probe techniques. The beneficial effect as well as the role of $\mathrm{Re}$ additions in the creep resistance of CMSX-2 and PWA 1480 alloys have been studied. Atom probe analyses show that very fine clusters, $10 \AA$ in size, are present in the matrix. Re additions also modify the partitioning of other elements. Other experiments conducted on a Re-free CMSX-2 alloy exhibit the occurence of a concentration gradient in the precipitates near the phase boundary. 


\section{INTRODUCTION}

Nickel base superalloys for turbine blades have constantly been improved through chemistry modifications and innovative processing techniques. Modern single crystal superalloys like CMSX-2 and PWA 1480 derive their excellent creep performance from the presence of a large volume fraction of ' $\gamma^{\prime}$ precipitates $(70 \%)$. High temperature properties strongly depend upon the lattice misfit which is in turn controlled by the phase composition. It is important to insist here that the misfit is closely related to the local concentrations of various elements in the vicinity of the $\gamma / \gamma$ ' interface. It is therefore of utmost importance to characterize the $\gamma$ and $\gamma^{\prime}$ phases chemically as well as the interface.

A number of refractory elements such as W, Ta, Mo and more recently $R e$ are added in nickel base superalloys in order to improve their mechanical strength. The element Re for instance has been shown to be a potent strengthener in creep of single crystal materials. However, the physical reasons behind the improvement in strength of Re containing superalloys have not been elucidated. The role played by these elements can be more subtle than just solid solution strengthening. The performances of superalloys are in effect, intimately dependent on the solute distribution in both $\gamma$ and $\gamma$ ' phase. For instance, the stacking fault energy as well as the antiphase boundary energy are probably two major parameters which determine the temperature capability of nickel base alloys. Both parameters are directly dependent one hand, upon the occurence of a short range order in the $\gamma$ solid solution and on the other hand, on the long range order in $\gamma^{\prime}$ particles.

The atom-probe techniques are well suited for the investigation of these fine scale microstructural parameters. This instrument is probably the most sensitive microanalytical tool currently available. Quantative informations can be obtained for a large variety of elements, including for the light species $(B, H)$. The spatial resolution of the apparatus may be varied from 5 to $25 \AA$ at the specimen surface. In addition, the depth resolution attains one atomic layer. This means that very fine $\gamma^{\prime}$ particles may be chemically analysed, small clusters (10 $\AA$ ) may be detected and interphase boundaries may be investigated as well. In addition, by making an atom-probe analysis of the (001) superlattice planes of the ordered $\gamma^{\prime}$ phase, one is able to estimate the occupancy frequencies of sites for each element, these parameters being deduced from the average composition of both types of planes (mixed and pure planes). In this paper, we will try to focus the attention on the information provided by this technique and discuss the possible consequences of fine scale features on the high temperature properties of superalloys.

\section{EXPERIMENTAL}

Principle of atom-probe

The FIM - atom-probe combines an ultra high resolution 
field ion microscope with a mass spectrometer of single atom sensitivity. The Field ion microscope provides an atomic resolution image of a specimen. The atom-probe is capable of performing chemical analysis with equal sensitivity for all elements and a spatial resolution of better than $1 \mathrm{~nm}$.

The principle of these techniques is based on field ionisation of a rare gas near the specimen surface (FIM) and controlled field evaporation of atoms. Both physical processes requirc a high clcctrical ficld. This is obtaincd by applying a positive voltage to the specimen prepared in the form of a sharply pointed needle. Atom probe investigations of a material may be interpreted as a layer by layer analysis along a cylinder whose the axis is parallel to the tip axis. The diameter of this cylinder is equal to the size of the area which is selected by the detector. More details may be found in a recently published paper [1].

Although atom-probe analyses do not necessitate the knowledge of some calibration parameters, care must be taken with the experimental conditions. The details of optimum operating conditions which are required to obtain reliable compositional data are discussed elsewhere [2].

\section{RESULTS}

Role of Re additions in improving creep resistance

Two base alloy chemistries, designated CMSX-2 and PWA 1480, were selected in this investigation. Rhenium was partly or entirely substituted for $w$ in these reference alloys. The chemical compositions (at $\%$ ) of various alloys are shown in Table I. The basic intention here is to study the role of $\mathrm{Re}$ in creep and not to propose optimized alloy chemistries for which further work is required in order to avoid phase instability. Single crystals were grown parallel to the (001) direction by the seeded technique under a temperature gradient of $250^{\circ} \mathrm{C} / \mathrm{cm}$ at a withdrawal rate of $15 \mathrm{~cm} /$ hour. All single crystal specimens for creep tests were within $5^{\circ}$ from (001) and given a solutioning and homogeneizing treatment between 1280 and $1325^{\circ} \mathrm{C}$ for 15 hours followed by air quenching and precipitation heat treatments at $1050^{\circ} \mathrm{C} / 16 \mathrm{~h} / \mathrm{AC}+850^{\circ} \mathrm{C} / 48 \mathrm{~h}$.

\begin{tabular}{|c|c|c|c|c|c|c|c|c|}
\hline Alloy & Al & Ti & Cr & Ni & Co & Ta & W & Re \\
\hline CMSX-2 & 12.21 & 1.25 & 9.22 & Bal. & 5.08 & 1.99 & 2.61 & - \\
\hline CMSX-2-4W-4Re & 12.21 & 1.25 & 9.22 & $\mathrm{Bal}$. & 5.08 & 1.99 & 1.30 & 1.29 \\
\hline CMSX-2-OW-5Re & 11.96 & 1.23 & 9.03 & Bal. & 4.98 & 1.95 & - & 1.58 \\
\hline PWA 1480 & 11.26 & 1.90 & 11.68 & $\mathrm{Bal}$. & 5.15 & 4.03 & 1.32 & - \\
\hline PWA 1480-Re & 11.26 & 1.90 & 11.68 & $\mathrm{Bal}$ & 5.15 & 4.03 & - & 1.31 \\
\hline
\end{tabular}

Table I. Nominal compositions of single crystal superalloys (at \%) 
Creep tests were run in the temperature range $850-1000^{\circ} \mathrm{C}$ and the results are reported in Table II. Clearly, the creep strength of the Re-modified alloys, despite the slightly lower volume fraction of the ' ${ }^{\prime}$ ' phase, is significantly higher than that of the base alloys at all temperatures. However, the improvement is most significant around $950^{\circ} \mathrm{C}$ both in the time for $1 \%$ creep and in stress rupture life.

\begin{tabular}{|c|c|c|c|c|c|c|c|c|c|}
\hline & CMSX-2 & $\begin{array}{l}\text { CMSX-2 } \\
4 \mathrm{~W}-4 \text { Re }\end{array}$ & $\begin{array}{l}\text { PWA } \\
1480\end{array}$ & $\begin{array}{c}\text { PWA } \\
1480-R e\end{array}$ & \\
\hline $\begin{array}{c}\text { Tempe- } \\
\text { rature } \\
\left({ }^{\circ} \mathrm{C}\right)\end{array}$ & Stress & $\mathrm{t}_{\mathrm{A}}$ & $\mathrm{t}_{\mathrm{B}}$ & $\mathrm{t}_{\mathrm{A}}$ & $\mathrm{t}_{\mathrm{B}}$ & $\mathrm{t}_{\mathrm{A}}$ & $\mathrm{t}_{\mathrm{B}}$ & $\mathrm{t}_{\mathrm{A}}$ & $\mathrm{t}_{\mathrm{B}}$ \\
$(\mathrm{MP})$ & $(\mathrm{h})$ & $(\mathrm{h})$ & $(\mathrm{h})$ & $(\mathrm{h})$ & $(\mathrm{h})$ & $(\mathrm{h})$ & $(\mathrm{h})$ \\
\hline 850 & 500 & 102 & 382 & 123 & 498 & 88 & 356 & 64 & 497 \\
\hline 950 & 240 & 141 & 390 & 265 & 646 & 125 & 354 & 220 & 580 \\
\hline 1000 & 200 & 60 & 176 & 106 & 315 & 52 & 118 & 71 & 223 \\
\hline
\end{tabular}

Table II. Effect of Re on creep properties of the (001) single crystal alloys

$$
\begin{gathered}
t_{A}: \text { Time to } 1 \% \text { creep } \\
t_{B} \text { : Rupture life }
\end{gathered}
$$

\begin{tabular}{|c|r|l|r|r|l|l|l|l|}
\hline $\begin{array}{c}\text { Composition } \\
\text { at } \%\end{array}$ & $\mathrm{~A} 1$ & $\mathrm{Ti}$ & $\mathrm{Cr}$ & $\mathrm{Ni}$ & $\mathrm{Co}$ & $\mathrm{Ta}$ & $\mathrm{W}$ & $\mathrm{Re}$ \\
\hline Matrix & 3.1 & 0.6 & 25.5 & 59.6 & 8.6 & 0.1 & 2.5 & 0 \\
\hline Precipitates & 16.7 & 3.0 & 2.4 & 70.5 & 3.2 & 3.0 & 2.4 & 0 \\
\hline
\end{tabular}

\begin{tabular}{|c|c|c|c|c|c|c|c|c|c|}
\hline $\begin{array}{c}\text { Composition } \\
\text { at. } \frac{\circ}{0}\end{array}$ & $\mathrm{Al}$ & & Ti & $\mathrm{Cr}$ & $\mathrm{Ni}$ & Co & & $\mathrm{Ta}$ & $\mathrm{Re}$ \\
\hline $\begin{array}{l}\text { Matrix } \\
\text { (33 } 000 \text { ions) }\end{array}$ & $\begin{array}{r}4.76 \\
\pm \quad 0.12 \\
\end{array}$ & \pm & $\begin{array}{l}0.2 \\
0.02 \\
\end{array}$ & $\begin{array}{r}20.12 \\
\pm \quad 0.22 \\
\end{array}$ & $\begin{array}{r}63.89 \\
\pm \quad 0.26 \\
\end{array}$ & $\begin{array}{ll} & 7.5 \\
+ & 0.15 \\
\end{array}$ & \pm & & $\begin{array}{r}3.59 \\
\pm \quad 0.1 \\
\end{array}$ \\
\hline $\begin{array}{l}\text { Precipitates } \\
(18000 \text { ions })\end{array}$ & $\begin{array}{r}16.59 \\
+\quad 0.27 \\
\end{array}$ & \pm & $\begin{array}{l}1.79 \\
0.25 \\
\end{array}$ & \begin{tabular}{|l|}
3.5 \\
$\pm \quad 0.14$ \\
\end{tabular} & $\begin{array}{r}71.7 \\
\pm \quad 0.34 \\
\end{array}$ & $\begin{array}{l}3.2 \\
0.13\end{array}$ & \pm & $\begin{array}{l}2.49 \\
0.11 \\
\end{array}$ & $\begin{array}{ll} & 0.52 \\
+ & 0.052 \\
\end{array}$ \\
\hline
\end{tabular}

Table III. Phase composition in CMSX-2

Table IV. Phase composition in

the CMSX-2-OW-5Re material

The mass spectrum of $\gamma$ phase of the CMSX-2-OW-5Re alloy is given in figure 1. This histogramm exhibits the main features of the matrix : while $\gamma^{\prime}$ precipitates are Al, Ti, Ta rich, the $r$ solid solution is a $\mathrm{Cr}$, Co rich phase. Re element appears in the $r$ spectrum in two charge states: $\mathrm{Re}^{2+}$ and $\mathrm{Re}^{3+}$. Phase composition of both phases are given in Table IV. It is clear that the Re partitions preferentially to the matrix. As shown in 
the Table IV, the partitioning ratio of this element is close to $7\left(\mathrm{C}_{\gamma} / \mathrm{C}_{\gamma},\right)$. Phase composition in the standard CMSX-2 alloy is given in Table III for comparison.

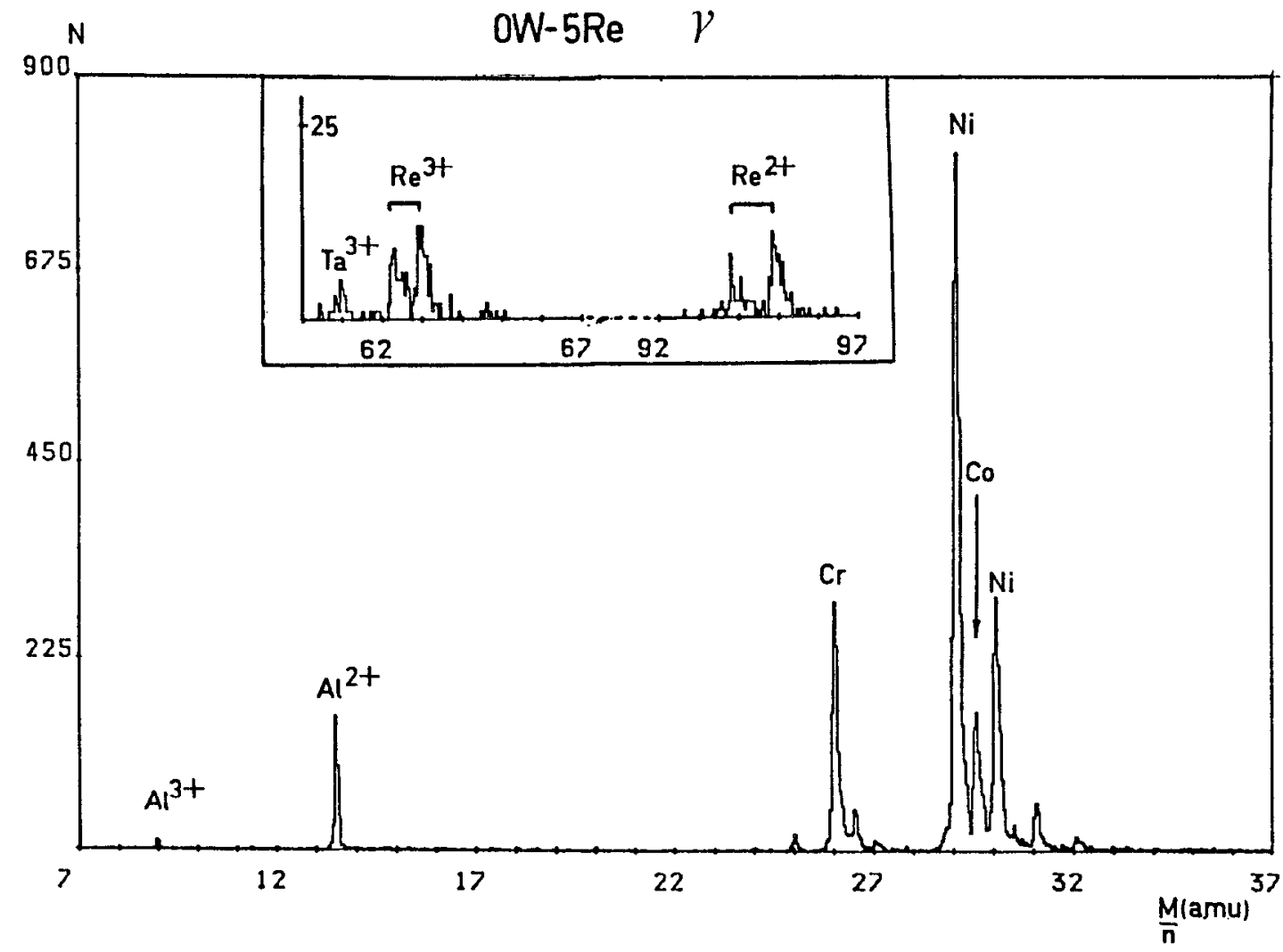

Figure 1 : Mass spectrum of $\gamma$ phase in the CMSX-2-0W-5Re alloy.

Figure 2 is a synthetic representation of atom-probe data shown in Tables III, IV, ㅁ, for the three CMSX-2 versions. This graph simply uses the well known lever rule :

$$
c_{n}=f c_{\gamma},+(1-f) c_{\gamma}
$$

$C_{\gamma}, C_{\gamma}$ are respectively the composition of $\gamma^{\prime}$ and $\gamma, C_{n}$ is the nominal composition of the material and $f$ the volume fraction.

Atom-probe results are reported here for the standard CMSX-2 as well as for two Re-modified versions. The fact that all experimental data for a given material are aligned along a single line proves that atom-probe analyses are consistent with the bulk composition of the material. The figure also clearly shows in addition that the Re addition reduces the partitioning ratios of $\mathrm{Al}$ and $\mathrm{Cr}$ elements $\left(\mathrm{C}_{\gamma},-\mathrm{C}_{\gamma}\right.$ decreases). However, no detectable change is observed for the volume fraction. The slope of the "best fit" line is close to $65 \%$ for each material. 


\begin{tabular}{|c|c|c|c|c|c|c|c|c|}
\hline $\begin{array}{c}\text { Composition } \\
\text { at } \%\end{array}$ & $\mathrm{Al}$ & $\mathrm{Ti}$ & $\mathrm{Cr}$ & $\mathrm{Ni}$ & $\mathrm{Co}$ & $\mathrm{Ta}$ & $\mathrm{W}$ & $\mathrm{Re}$ \\
\hline Matrix & 4.63 & 0.23 & 21.94 & 60.4 & 7.60 & 0.52 & 1.82 & 2.87 \\
\hline Precipitates & 17.22 & 1.87 & 3.23 & 70.0 & 3.27 & 2.99 & 0.90 & 0.41 \\
\hline
\end{tabular}

Table $\underline{\underline{J}}$. Phase composition in CMSX-2-4W-4Re

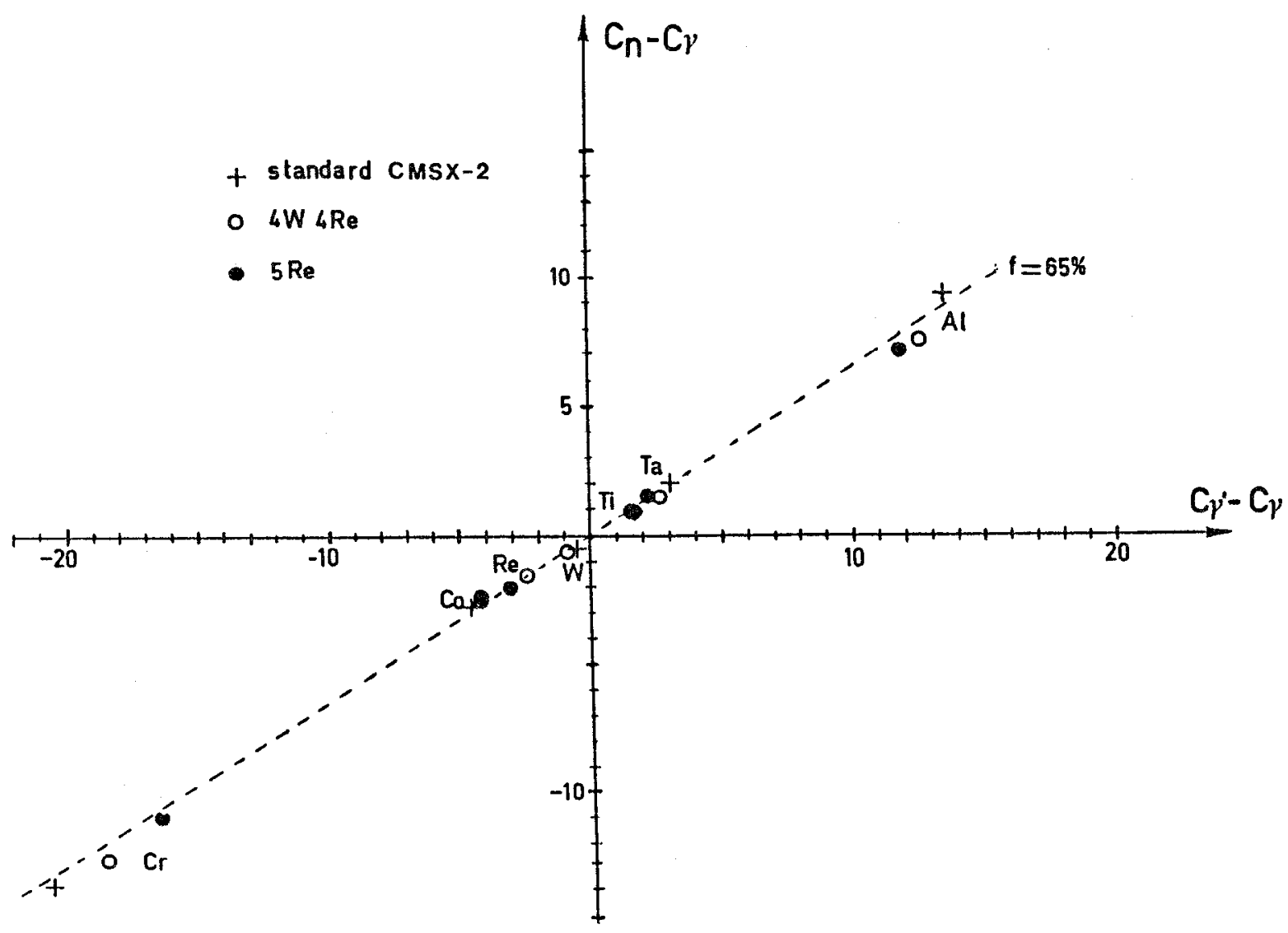

Figure 2 : Volume fraction diagramm. $c_{n}, c_{\gamma}, c_{\gamma}$, are respectively the nominal composition of the three materials and the composition of both $\gamma$ and $\gamma^{\prime}$ phases.

Among the fine-scale information provided by atom-probe techniques, the preferential sites of solute elements in the $\gamma$ ' ordered phase are of great interest. By performing an investigation of (001) superstructure planes of $r^{\prime}$, one is able to estimate the long range order in this phase [3]. The preferential sites of various elements may be deduced from the mass spectra of both the Al rich mixed planes and the $\mathrm{Ni}$ rich pure planes. The results as deduced from these spectra (figure 3 ) may be qualitatively interpreted as follows : Ti, Ta, $\mathrm{W}$ as well 
as Re are preferentially located in mixed planes. These elements substitute for $A l$ sites (cube corners). In contrast, the presence of $\mathrm{Cr}$ and $\mathrm{Co}$ in both types of planes suggests that these atoms preferentially substitute for $\mathrm{Ni}$ sites. These results are in qualitative agreement with the orientation of solubility lobes in ternary phase diagramms (Ni Al X) [4].
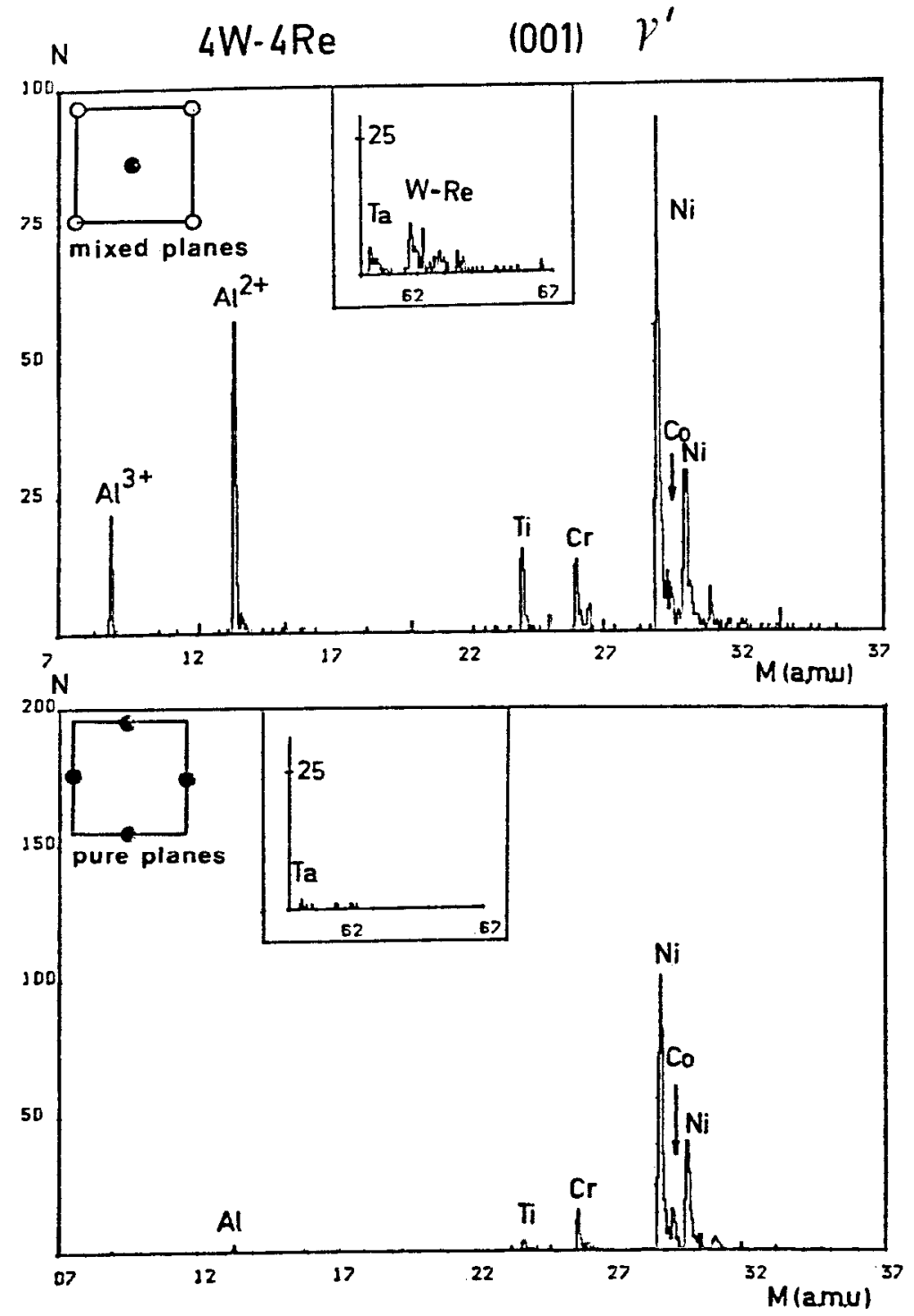

Figure 3 : Mass spectra of both types of (001) planes (mixed and pure planes) in the ordered $\gamma^{\prime}$ phase (CMSX-2-4W-4Re).

In order to establish a firm support for the observed improvement in creep resistance brought about by Re additions, it is important to investigate the spatial distribution of this element in the FCC solid solution.

The experiments we conducted on Re containing alloys revealed interesting informations. The matrix of both CMSX-2 and PWA 1480 superalloys was found to contain Re enriched clusters. The fine scale fluctuations of Re observed in the $r$ matrix of the PWA 1480 alloy are illustrated by figure 4. The phase composition of the PWA 1480 versions, as shown in Table JI, confirms that Re 
atoms segregate preferentially to the matrix. The rhenium profile clearly exhibits a small enriched region extending over $13 \AA$. The lateral resolution being of the same order as the apparent size of the cluster, the observed composition (as given by the curve slope) has to be considered as an integrated measurement of the small cluster and the surrounding matrix. The actual Re concentrations, computed from various clusters encountered, are between 20 and 90 at $\%$

\begin{tabular}{|c|r|c|r|c|r|c|c|c|}
\hline $\begin{array}{c}\text { Composition } \\
\text { at } \%\end{array}$ & \multicolumn{1}{c|}{$\mathrm{Al}$} & $\mathrm{Ti}$ & $\mathrm{Cr}$ & $\mathrm{Ni}$ & $\mathrm{Co}$ & $\mathrm{Ta}$ & $\mathrm{W}$ & $\mathrm{Re}$ \\
\hline Matrix & 2.79 & 0.17 & 34.03 & 49.26 & 11.01 & 0.56 & 2.15 & 0 \\
$\gamma$ precipitates & 15.40 & 2.85 & 2.17 & 70.10 & 3.10 & 4.59 & 1.68 & 0 \\
\hline Matrix & 2.54 & 0.31 & 34.22 & 47.79 & 11.00 & 0.33 & 0 & 3.71 \\
$\gamma^{\prime}$ precipitates & 15.35 & 3.09 & 2.31 & 69.97 & 2.88 & 5.64 & 0 & 0.76 \\
\hline
\end{tabular}

Table VII. Composition (at \%) of the $\gamma$ and $\gamma^{\prime}$ phases in PWA 1480 and PWA 1480-Re Alloys

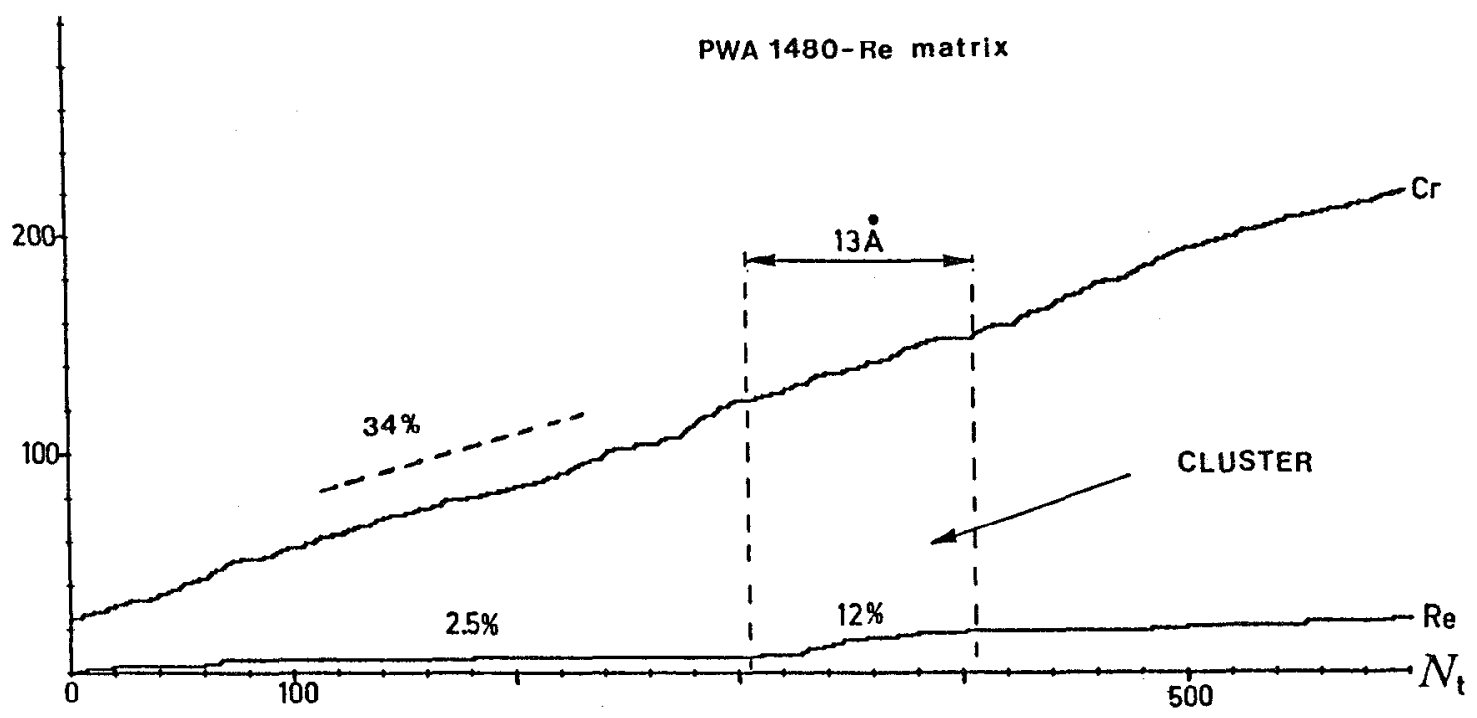

Figure 4 : Integral composition profile showing the presence of a Re enriched cluster in the matrix of PWA 1480 alloy. The cumulative number of detected ions (Re or $\mathrm{Cr}$ ) is plotted versus the total number of analysed atoms $\left(\mathrm{N}_{t}\right)$. The slope of each curve gives the local concentration. $\mathrm{N}_{t}$ is proportional to the probed depth.

\section{$\underline{Y} / Y^{\prime}$ interface}

Atom-probe techniques are also particularly suitable for the study of $\gamma / \gamma^{\prime}$ interfaces [5]. Figure 5 presents a concentration profile obtained in the vicinity of the phase boundary of the standard CMSX-2 material. This alloy was subjected to the standard two-stages precipitation treatment which consists in heat treating at $1050^{\circ} \mathrm{C}$ for 16 hours plus air quenching and then at $850^{\circ} \mathrm{C}$ for 48 hours. However, the $\gamma^{\prime}$ size distribution was found to remain monomodal [6]. 


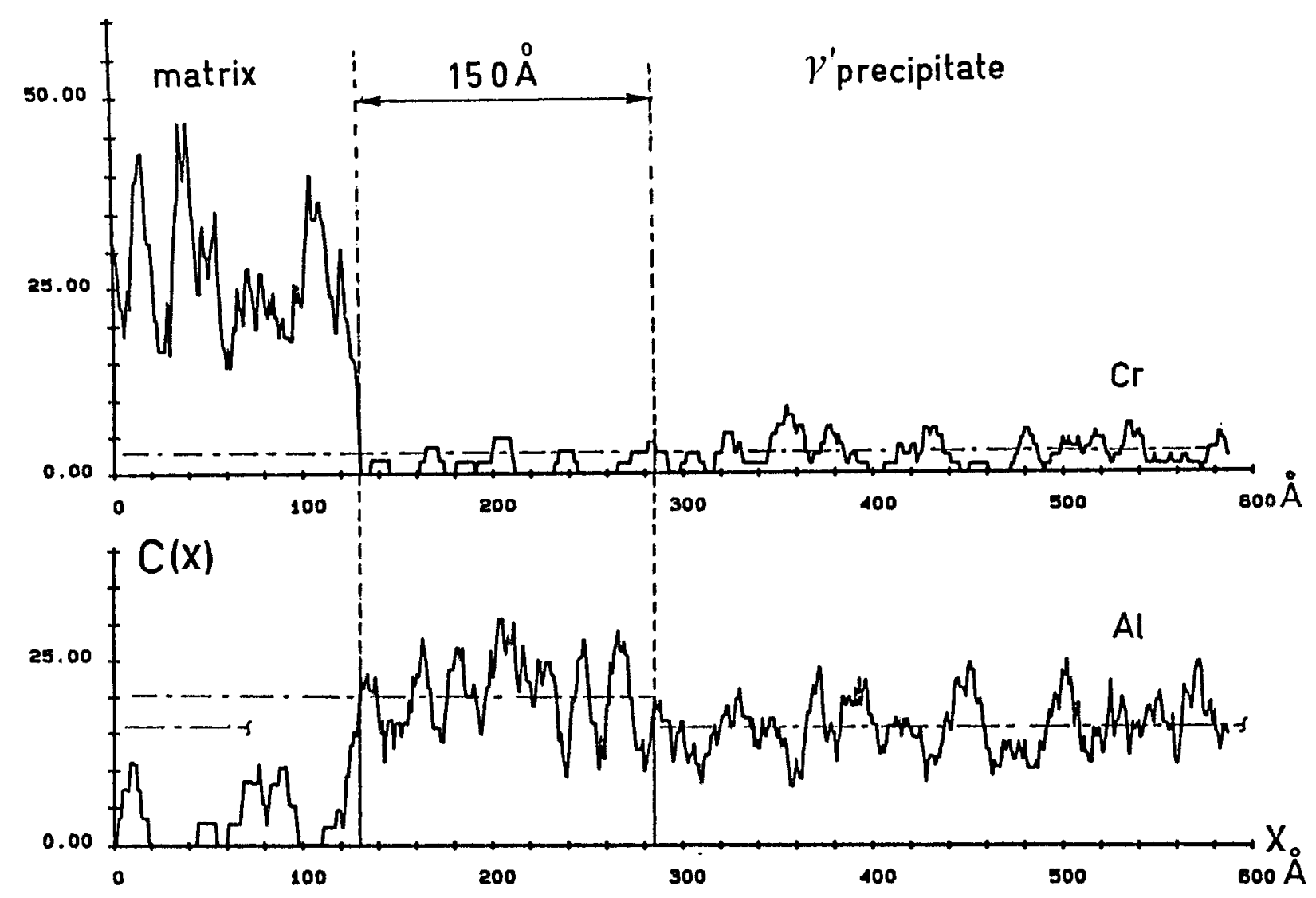

Figure 5 : Concentration profile showing the transition between the matrix and a precipitate in the standard CMSX-2 alloy. This figure clearly exhibits an Al enriched $\mathrm{Cr}$ depleted shell in the vicinity of the interface.

The profile clearly exhibits the occurence of a local concentration gradient in $\gamma^{\prime}$, near the interface. The width of the Al enriched region (or $\mathrm{Cr}$ depleted zone) is in good agreement with the observed increase of the $\gamma^{\prime}$ volume fraction due to the second precipitation heat treatment at $850^{\circ} \mathrm{C}$ for 48 hours. Indeed, the atom probe measurements show that this second heat treatment increaseas the volume fraction of the $\gamma^{\prime}$ phase by 5\% compared with the single stage heat treatment performed at $850^{\circ} \mathrm{C}$ only. This suggests that the occurence of this enriched region around $\gamma^{\prime}$ particles is due to a non-equilibium phenomenon. Although the physical mechanisms involved are not completely elucidated, it is thought that this zone is due to the growth of initially formed particles at $1050^{\circ} \mathrm{C}$ (first precipitation stage) during the second heat treatment at $850^{\circ} \mathrm{C}$.

\section{CONCLUSION}

The few examples described here show the importance of atom-probe techniques in the investigation of very fine scale features of superalloys. The investigations conducted on $\mathrm{Re}$ containing single crystal materials provide a physical basis for the observed improvement of the stress rupture properties of these materials. The experiments demonstrate that Re additions do 
not modify the volume fraction of $\gamma^{\prime}$ to any large extent. However a slight decrease in the partitioning ratios of $A I$ and $C r$ is observed. The studies conducted on long range order in $\gamma^{\prime}$ also showed that $\mathrm{W}$, $\mathrm{Ta}, \mathrm{Ti}$ as well as Re occupy the Al sites in the ordered ' $\gamma$ ' phase. Atom-probe analyses of both CMSX-2 and PWA 1480 alloys clearly revealed the occurence of small Re clusters in the matrix. These Re enriched regions probably act as more efficient obstacles against dislocation motion compared to isolated solute atoms in a $r$ solid solution. It is thought that these clusters must therefore play an important role in creep properties of $\operatorname{Re}$ containing superalloys.

With regard to the study of the $\gamma / \gamma^{\prime}$ interface in the CMSX-2 alloy, the microanalyses reveal the presence of an $A 1$ enriched region, $150 \AA$ in width, in the vicinity of the phase boundary. Since the creep performance of nickel base superalloys depends, in part, on the lattice misfit, we postulate that such a concentration gradient must have a strong effect on the mechanical properties of these alloys.

\section{ACKNOWLEDGEMENTS}

The authors wish to thank the Direction des Recherches, Etudes et Techniques (DRET) for its financial support (contract nr 84.1230 ).

\section{REFERENCES}

[1] D. BLAVETTE and A. MENAND "La sonde atomique et la microscopie ionique à émission de champ en Sciences des Matériaux," Annales de chimie 11 (1986) 321 - 384 .

[2] D. BLAVETTE, A. BOSTEL and J.M. SARRAU "Atom probe microanalysis of a nickel base superalloy," Met. Trans 16 A (1985) $1703-1712$.

[3] D. BLAVETTE et A. BOSTEL "Phase composition and long range order in $\gamma^{\prime}$ phase of a nickel base single crystal superalloy CMSX-2 : an atom probe study," Acta Met., 32 pp (1984) $811-816$.

[4] S. OCHIAI, Y. OYA, T. SUZUKI "Alloying behaviour of $\mathrm{Ni}_{3} \mathrm{Al}$, $\mathrm{Ni}_{3} \mathrm{Ga}, \mathrm{Ni}_{3} \mathrm{Si}$ and $\mathrm{Ni}_{3} \mathrm{Ge}, "$ Acta Met. $\underline{32}$ (1984) 289.

[5] D. BLAVETTE and A. BOSTEL "FIM atom-probe investigation of the interphase boundary of a nickel-base superalloy," Surf. Sci. Lett, 177 (1986) L994.

[6] P. CARON and T. KHAN "Improvement of creep strength in a nickel-base single-crystal superalloy by heat treatment," Mat. Sci. ang Eng. 61 (1983) 173 